Respiration 2018;96:302

DOI: $10.1159 / 000486796$

\section{Sildenafil-Bosentan Drug-Drug Interaction: A Word of Caution Regarding the Most Common Combination Therapy in Children with Advanced Pulmonary Arterial Hypertension}

\author{
Christian Apitz $^{\text {a }}$ Dietmar Schranz ${ }^{\text {b }}$ \\ a Division of Pediatric Cardiology, University Children's Hospital \\ Ulm, Ulm, Germany; ${ }^{b}$ Pediatric Heart Center, University \\ Children's Hospital Frankfurt/Giessen, Frankfurt, Germany
}

We read with great interest the article by Grünig and coworkers [1], who investigated plasma drug concentrations of 125 adult patients with pulmonary arterial hypertension (PAH) and found a substantial interaction characterized by insufficient sildenafil and elevated bosentan plasma concentrations in more than $70 \%$ of patients receiving the combination of sildenafil and bosentan. The sildenafil-bosentan drug-drug interactions were explained by the CYP-inducing effects of bosentan.

We are concerned about these data, which are alarming particularly for physicians who are involved in the treatment of children with PAH. While there are now eleven targeted drugs available for specific treatment of PAH in adults [2], only sildenafil and bosentan are currently approved by the European regulatory agency (EMA) for specific monotherapy of children with PAH, due to the lack of randomized controlled clinical studies [3]. And there is even less evidence regarding their combined treatment effects [4], although the combination of bosentan and sildenafil is undoubtedly the most common combination therapy for PAH in children worldwide.
With increasing use of this combination therapy especially in children with advanced PAH, the observed drug-drug interactions are of major concern. Insufficient sildenafil and too high bosentan plasma concentrations must be regarded as threatening particularly for patients with significantly impaired pulmonary endothelial function associated with poor prognosis in whom adequate combination therapy is necessary for survival [5].

According to the results of Grünig and coworkers [1], a conceivable approach towards solving this threatening problem might be the routine assessment of sildenafil-bosentan plasma concentrations, at least in patients with inadequate treatment response. If the corresponding sildenafil plasma concentrations are inadequately low, the switch from bosentan to an alternative off-label ERA (ambrisentan or macitentan) should be considered, ideally before suggesting treatment escalation to a triple combination therapy.

\section{References}

1 Grünig E, Ohnesorge J, Benjamin N, et al: Plasma drug concentrations in patients with pulmonary arterial hypertension on combination treatment. Respiration 2017;94:26-37.

2 Galiè N, Humbert M, Vachiery JL, et al: 2015 ESC/ERS Guidelines for the diagnosis and treatment of pulmonary hypertension: The Joint Task Force for the Diagnosis and Treatment of Pulmonary Hypertension of the European Society of Cardiology and the European Respiratory Society. Eur Heart J 2016;37:67-119.

-3 Latus H, Delhaas T, Schranz D, Apitz C: Treatment of pulmonary arterial hypertension in children. Nat Rev Cardiol 2015;12:244-254.

4 Douwes JM, Roofthooft MT, Van Loon RL, at al: Sildenafil add-on therapy in paediatric pulmonary arterial hypertension, experiences of a national referral centre. Heart 2014;100:224-230.

5 Apitz C, Zimmermann R, Kreuder J, et al: Assessment of pulmonary endothelial function during invasive testing in children and adolescents with idiopathic pulmonary arterial hypertension. J Am Coll Cardiol 2012;60:157-164.

\section{KARGER}

(c) 2018 S. Karger AG, Basel

E-Mail karger@karger.com

www.karger.com/res
Prof. Christian Apitz

Division of Pediatric Cardiology, University Children's Hospital Ulm Eythstrasse 24

DE-89075 Ulm (Germany)

E-Mail capitz@aol.com 